\title{
Psychoanalytic Understanding of 'Dukkha' in Buddhism: Based on 'Four Noble Truths' Part 1
}

\author{
Hyeong Hoon $\mathrm{Kim}^{1}$ and Jee Hyun $\mathrm{Ha}^{2}$ \\ ${ }^{1}$ Deparment of Psychiatry, Chuncheon National Hospital, Chuncheon, Korea \\ ${ }^{2}$ Deparment of Psychiatry, School of Medicine, Konkuk University, Seoul, Korea
}

\author{
불교에서 ‘고(苦)'의 정신분석적 이해: ‘사성제’를 중심으로 1 \\ 김형훈 ${ }^{1}$ 하지현 ${ }^{2}$ \\ ${ }^{1}$ 국립춘천병원 정신건강의학과, ${ }^{2}$ 건국대학교 의학전문대학원 정신건강의학교실
}

Recently, there has been an increasing interest in Buddhism in the field of psychiatry. Four Noble Truths is a primitive Buddhist teaching that deals with human suffering. Four Noble Truths relate to suffering, the cause of suffering, the cessation of suffering, and how to extinguish suffering. Suffering is called Dukkha in the old indian language. Authors analyzed the similarities and differences between Buddhism and psychoanalysis focused on 'suffering'. Four Noble Truths can be interpreted psychoanalytically in terms of cure for human suffering. First Noble Truth is a declaration that life is suffering. While Buddhism emphasizes the impermanence and selflessness in understanding suffering, psychoanalysis understands suffering as a developmental task and individual conflict based on previous experiences. In addition, while psychoanalysis pursues a healthy self, Buddhism rejects all conceptualization of the self and places importance on the selflessness. In conclusion, Buddhism and psychoanalysis have a common point of dealing with human suffering, but there is a difference between the treatment methods and the ultimate goals.

Psychoanalysis 2021;32(4):117-126

Keywords: Psychoanalysis; Buddhism; Religion; Culutre.

Received: June 7, 2021 Revised: September 11, 2021 Accepted: September 18, 2021

Address for correspondence: Jee Hyun Ha, MD

Deparment of Psychiatry, School of Medicine, Konkuk University,120 Neudong-ro, Gwangjin-gu, Seoul 05029, Korea

Tel: +82-2-2030-7569, Fax: +82-2-2030-7748, E-mail: jhnha@naver.com

\section{서 론}

20세기 이후 과학기술의 발전과 국가별 교류의 일상화가 이루어지고 인터넷이 보급되면서, 백 년이 안되는 사이에 삶 의 형태가 급격히 변화하고 있다. 살아가는 환경의 변화는 그 안에서 살아가는 사람의 내적 심리 기제의 변화를 동반 한다. 전반적으로 물질적으로 풍요로워지고, 환경은 안전해 졌으며, 정보의 취득과 학습은 용이해졌지만 그에 비례해 정 신적 안정감을 획득하기보다 도리어 공허감을 호소하는 사 람들이 증가하고 있다. 따라서 우울과 불안을 경험하는 사람 이 많아지면서 종교나 명상 등에 대한 관심이 커지고 있다.

This is an Open Access article distributed under the terms of the Creative Commons Attribution Non-Commercial License (https://creativecommons.org/licenses/by-nc/4.0) which permits unrestricted non-commercial use, distribution, and reproduction in any medium, provided the original work is properly cited.
이 중 종교는 인간 정신문화 양식의 하나로 경험을 초월한 존 재인 신(神)을 믿거나, 우주(宇宙)와 관련한 큰 개념을 이해함 으로써, 인간 존재의 미시성과 죽음 이후의 세계와 이해하기 어려운 세상 이치를 이해하는 틀을 제공한다. 이를 통해 인 간은 불안이나 죽음과 같은 고민을 받아들이고 극복하는데 도움을 받고 초월적 사고를 하거나 신이라는 거대한 존재에 대한 의존을 통해 자기 존재의 미약함을 상쇄하려고 한다.

불교(佛教; Buddhism)는 기원전 6세기경 인도의 고타마 싯다르타에 의해 시작된 종교이다. 불교는 싯다르타가 펼친 가르침이자, 진리를 깨달아 붓다(Buddha; 깨달은 사람)가 될 것을 목표로 한다. 불교의 창시자는 붓다로 알려져 있지 만, '붓다'는 본래 고유명사로 “깨달은 이”를 의미한다. 하지 만 현재는 고타마 싯다르타를 의미하는 보통명사로 사용된 다. 불교는 기원이 오래된 종교로 동양 문화권에 많은 신도 가 있는데, 20세기 중반 이후 과학문명이 발달하고 서구화가 
전세계적으로 진행하면서 거꾸로 서구 문화권을 중심으로 불교에 대한 관심이 증가해 철학, 심리학 등 여러 영역에서 활발하게 연구되었다. 그리고 일상에서도 다양한 방식으로 도입되고 있다.

이미 기독교적 세계관이 확고한 서구 사회에서 불교가 받 아들여진 것은 불교가 종교적 영역에 속한다고 하더라도 신 과 같은 초월적 존재를 믿는 타종교들과 다른 면이 있기 때 문이다. 인간은 자기를 보호해줄 신을 찾거나, 또한 자기 보 존을 위해 영원불멸하는 자기 개념(나; 我)을 만들어낸다. 무지와 나약함과 두려움과 욕망 속에서 인간은 자기를 위로 할 두 가지를 필요로 했던 것이다(Choi와 Shin 2005). 이와 달리 붓다는 '신'과 '나'라는 개념에 대해 정면으로 다른 견해 를 가졌다. 붓다는 세상을 지배하는 신에 의존하거나 '나'라 는 자기 개념에 도취되는 대신 연기(緣起)야 말로 세상의 진 리라고 했다. 연기는 세상의 모든 현상이 원인과 결과라는 인과(因果)의 법칙에 따라 구성되어 있으며, 상호간의 관계 성과 의존성 안에서 일어난다는 것이다. 이에 따르면 세상의 어느 것도 따로 떨어져 홀로 존재할 수 없고, 그 실체가 없이 단지 조건에 의해 생겨나고 조건이 다하면 소멸할 뿐이라는 것이 연기의 원리다. 붓다는 이러한 연기를 아는 것이 깨달 음의 길이라고 하였다. 따라서 불교의 기본 교리인 삼법인 (三法印), 사성제(四聖諦), 오온(五蘊) 등이 모두 연기의 구조 로 구성되어 있다.

이 중에서 '사성제(四聖諦; Four Nobel Truths)'는 붓다 최 초의 가르침이자, 붓다 자신의 경험으로서 불교 수행의 중심 으로 알려져 있다. 사성제는 인간 존재의 '고통'과 그 해결법 에 대해서 다루고 있는데, 의학적 측면에서 질병에 대한 접 근법과도 유사한 면이 있다. 사성제는 인간이 경험하는 고통 의 본질을 이해하려 하고, 그 고통을 인식하고 해결하는 과 정을 삶의 전반적 통찰의 측면에서 바라본다. 정신분석에서 고통을 바라보는 관점과도 맥락적으로 비슷한 점이 있다. Freud는 정신분석을 만들면서 신경증 치료란 히스테리로 인한 비참함(hysterical misery)을 보편적인 불행(common unhappiness) 정도로 바꾸는 것을 목적으로 한다고 하였다 (Freud와 Breuer 1895). 불교와 정신분석은 인간의 고통을 해결하는 방법과 그 최종 목표가 다르지만, 인간의 심리적 고 통을 다룬다는 점에서 공통점이 있다.

저자들은 사성제에서 중심적으로 다루는 주제를 정신분 석적 측면에서 공통점과 차이점에 주목하였다. 그 중 불교의 '고(苦)'는 정신분석, 정신의학에서 가장 중요하고 빈번하게 만나는 인간 마음의 고통과 가장 밀접한 연관을 갖고 있는 주제다. 불교와 정신분석은 고통에 대한 이해와 해결하는 방 법은 전혀 다르지만, 유사점과 차이점을 비교 분석함으로써
현대 정신분석적 관점이나 정신분석적 치료에서 받아들일 부분이 있을 가능성이 있다고 생각하였다. 논문은 총 2 부로 계획하였고 불교의 대표적 주제인 사성제 중 고성제(苦聖 諦)와 집성제(集聖諦)의 개별적 내용을 각각 분석할 것이다. 첫 번째 논문에서는 고성제를 중심으로 불교의 '고'의 개념 이 정신분석과 어떤 관계가 있는지 비교할 것이다.

\section{사성제(四聖諦; Four Noble Truths)}

사성제는 붓다가 최초로 베푼 가르침으로 초전법륜경 (Dhammacakkappavattana Sutta)에 실려 있다. 사성제의 “성(聖)'은 “성스러운”이라는 뜻을 지니고 있고, '제(諦)'는 “깨 우침 또는 진리”를 뜻하는 것으로, 사성제는 “네 가지의 높은 깨우침" 또는 “네 가지의 고귀한 진리(Four Noble Truths)"를 의미한다. 사성제는 고성제(苦聖諦), 집성제(集聖諦), 멸성제 (滅聖諦), 그리고 도성제(道聖諦)로 이루어져 있으며 각각의 의미를 지니고 있다(Table 1). 흔히 이 네 가지를 간단히 고 집멸도(苦集滅道)라고 부른다.

고성제는 인간의 삶은 본디 고통스럽다는 것이며, 집성제 는 인생의 고통의 원인은 갈애(渴愛)라는 것, 멸성제는 고통 의 원인을 완전히 없앨 수 있다는 것을 설명한다. 마지막으 로 도성제는 고통의 원인을 없애는 방법을 이야기한다. 붓다 는 사성제야말로 깨달음으로 나아가게 하는 실제 길이라고 하였다(Bhikkhu Kakmuk 2010).

불교의 고통인 '고'는 옛 인도 말인 팔리어로 '두카(dukkha)' 라고 한다. '두카'를 한역(漢譯)한 것이 '고'이고, 영어로는 'suffering', 한글로는 '고통'이다. '두카'는 원어의 뜻으로 수레바 퀴에 탈이 생겨 제 기능을 하지 못하는 상태를 의미하는데, 불만족스럽고 불안정한 상태를 말한다. '두카'는 일반적으로 만연한 삶의 불만, 불만족 등으로 번역하는 것이 더 옳다는 견해도 있다. 따라서 하나의 단어로 ‘두카’의 참 뜻을 완전히 포착하는 것은 불가능하기에 번역하지 않고 그냥 '두카'로

Table 1. Meanings of Four Noble Truths

\begin{tabular}{ll}
\hline $\begin{array}{c}\text { 사성제 } \\
\text { (Four Nobel truths) }\end{array}$ & 의 미 \\
\hline $\begin{array}{c}\text { 고성제(苦聖諦) } \\
\text { (First Noble truth) }\end{array}$ & 인간의 삶은 본디 고통이다. \\
집성제(集聖諦) & 고통의 원인은 갈애(渴愛; Craving)이다. \\
(Second Noble truth) & \\
멸성제(滅聖諦) & 고통의 원인을 제거(멸; 滅)할 수 있다. \\
(Third Noble truth) & \\
도성제(道聖諦) & 고통의 원인을 제거하는 방법(도; 道)이 \\
(Fourth Noble truth) & 있다. \\
\hline
\end{tabular}


두는 것이 최선인지도 모르겠다(Kostner 2015). 논문에서는 일반적인 단어로 '고통'을 사용할 것이다.

\section{고성제(苦聖諦; First Noble Truth)}

고성제는 모든 인간의 삶이 고통스러울 수밖에 없다는 붓 다의 사성제 중 첫 번째 선언이다. 초전법륜경에서 붓다는 고성제에 대해 다음과 같이 설명한다.

비구들이여, 태어남도 고통(생고; 生苦)이고, 늙음도 고통(노 고; 老苦)이고, 병듦도 고통(병고; 病苦)이고, 죽음도 고통(사고; 死苦)이다. 싫어하는 사람과 만나는 것도 고통(원증회고; 怨憎會 苦)이고, 사랑하는 사람과 헤어지는 것도 고통(애별리고; 愛別離 苦)이며, 구하는 것을 얻지 못하는 것도 고통(구부득고; 求不得 苦)이다. 요약하자면 취하여 집하는 몸과 마음의 환경은 모두 고통 (오취온고; 五取藴苦)이라는 것이 고통에 관한 신성한 진리이다.

붓다가 말한 여덟 가지 고통은 팔고(八苦)라고 하며, 태어 남, 늙음, 병듦 그리고 죽음은 생로병사(生老病死)의 네 가지 고통인 사고(四苦)로 잘 알려져 있다. 원증회고, 애별리고, 그리고 구부득고는 인생이 원하는 데로 흘러가지 않고 끊임 없이 변화한다는 무상(無常)의 원리를 보여준다. 오취온고 는 인간이 '자기'라는 것에 집착함으로써 생기는 고통으로 무아(無我) 사상과 연결되며, 모든 고통을 요약하는 핵심 고 통이다. 본 논문은 불교의 핵심 교리인 삼법인(三法印)을 먼 저 살펴보고 상기의 여덟 가지 고통들을 각각 정신분석적으 로 해석해보고자 한다.

\section{삼법인(三法印)}

삼법인은 불교의 기본 교리로 일체개고(一切皆苦), 제행 무상(諸行無常), 그리고 제법무아(諸法無我)로 구성된다.

일체개고는 “모든 것은 고통이다."라는 불교의 핵심 사상 이다. 불교는 모든 존재가 고통이라는 가르침을 전제로 하며, 세상과 우주의 모든 존재 및 현상이 고통이라고 설명한다. 특히 고성제는 인간의 삶이 고통스럽다는 것을 의미한다. 이 러한 불교의 입장에 대한 반론이 있을 수 있다. 일반적인 관 점에서는 인생은 고통만 있는 것이 아니라 즐거움도 있다. 따라서 인생이 고통이라고만 생각하지는 않는다. 하지만 불 교에서 의미하는 고통은 인간의 고통스러운 감정이나 상황 만을 의미하지 않는다. 불교는 개별적인 사건들의 고통을 이 야기하는 것이 아니라 삶과 우주 전체를 아우르는 고통을 이야기하는 것으로, 고통이 완전히 소멸된 열반(涅槃)의 상 태를 전제로 하여, 그 외의 상태를 모두 고통으로 바라본다.
Freud (1930)는 인생은 힘들고, 너무 많은 고통과 실망과 과제를 인간에게 안겨준다고 하였다. 또한 고통은 세 가지 방향으로부터 우리를 위협하는데 우리 인간의 육체, 외부세 계, 그리고 타인들과의 관계로부터 온다고 하였다. 이러한 Freud의 언급은 인생이 고통이라는 점에서 불교와 유사한 측면을 보인다. 하지만 고통에 대한 접근 방법은 사뭇 다르 다. 불교가 우주론적인 관점에서 모든 존재와 현상이 고통이 라고 이야기하면서 인간도 예외가 아니라고 한다면, 정신분 석은 인간의 증상과 고통을 개별적 한 개체의 측면에서 바 라보며, 고통이 있는 사람도 있고 없는 사람도 있다고 본다. 더 나아가 고통은 자아의 기능에 따라 줄어들거나 사라질 수 있다. 그래서 둘 사이에 고통을 해결하는 방법과 목표의 차이가 존재한다.

일체개고의 원인은 제행무상과 제법무아가 된다. 세상은 항상 일정하지 않고 끊임없이 변화한다는 무상과, '나'라고 믿고 있는 개념은 실제로 존재하지 않는다는 무아로 인해 고통스러울 수밖에 없다는 것이다.

제행무상은 “세상에 일정하게 존재하는 것은 없다.”라는 의 미로 붓다는 연기를 통해서 "조건으로 이루어진 모든 현상은 조건에 따라 변하고 항상 일정하지 않다.”고 했다. 인과 법칙 에 따라 우주는 끊임없이 변화하고 이러한 변화 속에서 인간 은 살아간다. 불교는 세상이 이와 같이 무상하기 때문에 모 든 것은 고통이라고 설명한다. 하지만 세상이 무상하다고 해 서 무조건 고통스러울 수밖에 없다고 이야기하지는 않는다. 불교는 조건에 따라 이루어진 현상들은 결국 조건에 따라 소 멸된다고 하면서, 인간이 세상이 변하지 않을 것이라는 기대 는 환상에 불과하다는 것을 이해해야 한다고 한다. 즉 문제 는 무상을 대하는 인간의 태도이지 무상 그 자체가 아니다 (Olendzki 2012). 인간의 고통은 무상을 이해하지 못하는 과 정에서 변화에 대한 거부를 하면서 발생하는 것이다. 그러므 로 무상을 이해할 때 고통이 줄어들 수 있다.

세상은 일정하지 않으며, 항상 변화한다는 무상에 대한 통 찰은 불교에서 중요한 수행의 하나이다. 정신분석은 변화의 불가피성을 인정은 하지만, 그보다 무의식에 집중한다. 그리 고 무의식에 존재하는 과거의 경험과 정서적 기억을 자아가 제대로 통제하지 못하여 고통이 발생한다고 본다. 비록 정신 분석이 '정신역동(psychodynamic)'이라는 의미를 사용하고 역동적 변화와 상호작용을 중시하지만 전체적으로 보면 한 개인의 과거로부터 선형적(linear)으로 현재가 존재한다는 가정을 갖는다. 불교는 치료적인 접근에 있어서도 정신분석 과 분명한 차이점을 보인다. 불교는 '무상'에 대한 통찰을 중 요시한다. 연기의 법칙에 따라 조건으로 이루어진 모든 현상 은 결국 조건에 따라 소멸하기 때문에 현상이 그대로 유지 
되기를 바란다는 것 자체가 고통을 유발한다는 것이다. 중요 한 것은 변화가 끊임없이 일어난다는 사실이고, 변화를 거부 할 수 없음을 이해하고 받아들이는 것이다. 그리고 그 변화 에 수반하는 각각의 고통은 나중의 문제이며, 가장 먼저 해 야 할 것은 무상을 이해하는 것이다. 반면에 정신분석은 변 화로 발생한 고통과 증상에 더욱 집중하고 이에 대한 원인 을 찾으려 한다. 그중 어린 시절의 경험과 부모와의 관계, 정 신성 발달 단계의 고착이나 결함에 주목한다. 불교는 우주론 적인 입장에서 고통에 대한 보편적 특성을 이해하고 통찰을 만들어낸다. 반면 정신분석은 인간 개개인의 입장에서 고통 에 대한 통찰을 이끌어낸다. 무의식에 여러 형태로 억압되어 있던 과거의 기억을 재구성하고 지금의 인생에서 다시 통합 하면서 새로운 서사를 만드는 것을 치료의 과정으로 본다는 점이 불교와 다른 점이다.

마지막으로, 제법무아는 "세상에 존재하는 모든 사물(事 物)은 인연으로 생겼으며 변하지 않는 참다운 자아의 실체 는 존재하지 않는다.”라는 뜻이다. 자아의 실체가 존재하지 않지만 자아의 실체가 존재한다고 믿고 있기 때문에 고통이 발생한다는 의미이다.

온 우주는 고정된 상태 혹은 고정된 실체로써 존재하지 않고 끊임없는 변화 속에서 존재한다. 이러한 무상의 원리가 자아에 적용이 되면 무아가 된다. '무아'는 연속적이며 불변 하는 실체로서 존재하는 자아(自我)에 대한 부정이다. 불교 의 무아는 자기 혹은 자아가 없다는 뜻으로 오해되지만 실 제 의미하는 바는 다르다. 무아는 고정된 자기(constant self) 나 고정된 자아(constant ego)는 허상이라는 의미를 내포한 다. 다시 말해 불교적 관점에서 자기 혹은 자아라고 불릴 수 있는 현상은 존재하지만 변하지 않고 실체하는 자기 혹은 자아는 존재하지 않으며, 자기 혹은 자아도 연기의 법칙에 따라 생성되고 소멸되며 영원불멸하지 않는다. 불교의 자기 혹은 자아에 대한 인식은 고통을 해결하는 최종 목표에서 정신분석이 자아 기능을 강하게 하고 건강한 자기를 추구하 는 것을 목표로 한다면, 불교는 이러한 자아와 자기에 대한 개념 자체를 거부하는 것을 목표로 한다는 점에서 차이를 보인다. 그렇지만 전체적으로 볼 때 정신분석에서의 고통은 변화를 거부하는 경직된 자아/초자아로부터 기인하는 경우 가 많다. 이러한 경직된 정신 구조가 환경의 변화나 관계의 변화에 비적응적인 기능을 하여 생기는 문제들을 해결하고 자 하는 것은 정신치료에서 내외적인 변화에 따라 개인도 함께 적응을 위한 변화가 필요하다는 인식에서 시작한다. 정 신치료로 얻은 통찰을 훈습(working through)하는 과정이 지난하고 더딘 이유도 변화의 필요성을 인식하는 것에 대한 개인의 어려움 때문이다. 그런 면에서 위의 삼법인적 관점은
정신분석이 지향하는 부분과 유사한 맥락으로 볼 부분이 많다.

이제 고성제의 각각의 고통에 대해 하나씩 살펴보도록 하 겠다.

\section{사고(死苦)}

붓다가 생사(生死)의 문제를 해결하기 위해 출가를 한 것 에서 알 수 있듯이 죽음은 불교에서 중요한 주제이다. 불교 는 다른 종교들과 마찬가지로 죽음을 다루지만 죽음을 바라 보는 접근법이 다르며, 죽음을 바로 직면시킨다. 죽음의 문 제는 어떤 인간도 피할 수 없지만, 인간은 이를 두려워하고, 때로는 두려워하고 있다는 사실도 자각하지 않으려고 한다. 하지만 불교는 죽음이야말로 인간에게 있어 실질적인 문제 이기 때문에 죽음을 회피하지 않도록 한다.

인간은 삶(生)과 죽음(死)을 반대되는 사건으로 인식하는 경향이 있다. 하지만 붓다는 태어남을 원인으로 하여 죽음이 라는 결과로 귀결된다는 연기의 논리로 둘을 연속선상에 놓 는다. 붓다는 연기를 통해 삶과 죽음이 따로 분리되지 않는 다는 것(불이; 不二)과, 본질적으로 둘이 다른 것이 아니라는 입장을 취한다. 이 둘은 연속적이며 상호의존적인 것으로서 서로가 서로를 전제한다(An 2006). 붓다의 관점에서 삶과 죽 음은 분리되는 것이 아니고, 서로 떼어낼 수 없는 현상인 것 이다.

이런 견해는 정신분석과도 다르다. 죽음은 삶의 종결이고 모든 것의 끝이다. 인정하고 싶지 않지만 모든 존재는 죽을 수 밖에 없다는 사실을 받아들이는 것은 인간 성숙의 중요 한 요소 중 하나다. 이중 욕동의 측면에서도 리비도와 타나 토스는 '생과 사'라는 전혀 다른 반대 방향의 두 가지 욕동을 상징한다. 정신분석이 삶과 죽음이라는 현상을 반대되는 것 으로 전제하면서 삶과 죽음을 향한 두 가지의 전혀 다른 욕 동을 자아가 적절히 통제하는 것을 목표로 한다면, 불교는 삶과 죽음이 다르지 않고 서로 상호의존적이라는 인식으로 부터 출발한다는 점에서 차이점을 보인다.

Freud (1915)는 모든 사람들이 죽음에 대한 생각을 지워 버리려 하는 특징이 있다고 하였다. 그에 따르면 인간은 본 능적으로 죽음을 믿으려하지 않으며, 무의식적으로 불멸에 대해 확신하려는 경향이 있다고 했다. 그러면서 Freud는 죽 음에 대한 인간의 불안을 유년기의 갈등을 은폐하는 신경증 적인 것으로 보았다. 인간이 죽음을 거부하고 부정하는 경향 이 있다고 하는 Freud의 설명은 불교와 유사하지만 그 원인 에 대해서 불교는 삶과 죽음을 분리하기 때문으로 이해하지 만 정신분석에서는 유년기의 신경증적 갈등으로 설명한다 는 차이점이 있다. 반면에 Erikson (1968)은 죽음에 대한 불 안은 심리사회적 마지막 발달단계인 자아통합(ego integra- 
tion)과 절망(despair)간의 갈등에서 일어나는 발달 과제라 고 인식했다. 자신의 삶을 긍정적으로 수용하며 자아통합을 이루면 죽음에 대한 불안도 줄어들지만, 무가치감과 절망감 에 빠지면 죽음에 대한 불안이 심해진다고 하였다. Erikson 은 죽음에 대한 인식과 수용이 노년기에 이루어져야 할 과 제로써 인식하는데 반해서 불교에서는 죽음을 가장 먼저 직 면해야 할 문제로 인식한다.

불교적 관점에서 인간은 죽음에 대한 생각을 은폐하기 때 문에 삶이라는 실제적인 고통을 해결할 수 없다. 불교의 생 사관은 정신분석적 관점에서 보면 인간이 죽음과 삶을 분열 (splitting)시키고, 삶을 이상화하고 죽음을 평가 절하하고 있 다고 볼 수 있다. 그리고 부정당한 죽음의 문제는 삶을 온전 히 바라보지 못하게 만든다. 삶은 삶 자체로 고통스럽지만 결국 가장 커다란 고통인 죽음을 맞이해야 한다. 죽음 앞에 서 삶의 개별적인 고통은 작은 고통에 불과해진다. 그렇다고 불교가 삶을 부정하는 방식으로 인식을 전개하지 않는다. 붓 다는 죽음이라는 인간의 존재론적인 문제를 삶과 통합하려 는 시도를 한다. 그러면서 괴로움의 근원이 되는 생사는 근 본적으로 변화시킬 수 없지만 원인과 결과에 따라 생성되고 소멸되는 연기를 이해하도록 함으로써 인생의 태도를 변화 시킨다. 이러한 태도는 외부 현실의 변화가 아니라 고통을 받아들이는 인간의 내면적이고 주관적인 반응의 변화를 일 으킨다.

불교는 연기를 통해서 모든 현상은 다양한 조건에 의해 상호적으로 의존되어 있고 서로 연결되어 있다고 설명한다. 정신분석에서도 정신결정론(psychic determinism)을 통해 서 어린 시절 초기의 경험이 인생을 통해 영향을 미친다고 보며 원인과 결과라는 인과법칙을 따른다는 측면에서 불교 의 연기와 유사한 측면을 보인다. 하지만 정신분석은 이러한 인과법칙을 인간의 개별적 정신내적 세계에 국한시켰으나, 불교는 인간과 자연 등 모든 세상의 범위로 확대하고 있다 고 볼 수 있다(Kim 2001).

\section{생고(生苦)}

불교는 죽음 이후에 다시 삶이 반복된다는 윤회(輪迴) 사 상을 기반으로 한다. 붓다가 고민한 문제는 고통으로 인식되 는 삶과 죽음, 그것도 '끝없이 반복되는' 윤회의 삶과 죽음이 라는 속박에서 어떻게 벗어날 것인가 하는 문제였다. 따라서 불교는 인간이 괴로운 이유를 생로병사(生老病死)의 굴레에 속박되어 있기 때문이라고 설명한다. 붓다의 깨달음은 모든 세상은 연기의 법칙에 따라 돌아간다는 것이다. 생로병사도 이와 같은 연기를 따른다. 태어남이 있기 때문에 인간은 늙 어갈 수 밖에 없고, 늙기 때문에 병이 들기 마련이며, 그리고
결국에는 죽음을 맞이한다. 그리고 죽음 뒤에는 윤회를 통해 다시 태어나게 되는데, 인간은 이러한 생사의 굴레를 피할 수 없다. 불교에서 말하는 깨달음은 바로 이러한 생사의 연 기를 이해하는 것이다.

불교는 윤회사상을 따르기 때문에 죽으면 다시 태어난다 고 본다. 태어난다는 사건은 고통스러운 삶을 반복하는 것이 기 때문에 생고가 된다. 만약 이 고통을 해결한다면 다시 태 어나지 않게 되는 열반, 해탈(解脫)이라는 깨달음의 경지에 오르게 된다. 반면에 정신분석은 윤회와 같은 순회형 ( $\mathrm{circu}^{-}$ lar) 모델이 아닌 선형적(linear) 모델이다. 인간은 태어나서 발달해 가고, 어떤 문제가 생기면 정신발달의 고착(fixation) 이 되거나 결함(deficit)이 발생한다. 그 영향으로 정신적 고통 을 경험한다고 이해한다. 그리고 그 문제점이 해결되면 다시 멈칬던 발달을 이어나갈 수 있을 것이라는 개념적 틀을 갖고 있다. 태어나서 죽을 때까지의 과정은 이런 선상 위에 있다.

Freud (1915)는 욕동이 정신과 신체 사이의 접경 개념으로, 유기체의 내부로부터 생겨나 마음에 도달한 자극들에 대한 표상으로 활동하도록 요구하는 어떤 것이라고 하였다. Freud 는 인간이 태어나면서 가지는 이러한 욕동을 인간 활동의 동 기로 보았다(Auchincloss 2015). 정신분석적 관점에서는 '태 어남(birth)'은 고통이라기보다는 리비도 혹은 본능이 처음 생 기는 것, 그리고 생성(生成), 생산(生産)과 관련되어 있기 때문 에, 고통의 영역보다 에너지의 근본으로 본다는 점에서 불교와 차이점을 보인다.

불교는 윤회사상을 바탕으로 태어남의 고통을 이야기하면 서 깨달음의 필요성을 설명하고, 끊임없이 반복되는 삶의 고 통을 해결하도록 촉구하지만 삶에 대한 회의적인 태도를 조 장하는 것은 아니다. 불교는 연기를 이해하고 삶과 죽음을 연 속적인 과정으로 이해하면서 삶 자체를 이해하고 수용할 수 있도록 도와준다. 반면에 정신분석은 태어남을 생성과 생산 이라는 측면에서 이해하기 때문에 윤회사상을 기반으로 하 는 불교와의 차이점을 보이고, 이러한 차이는 불교의 종교적 인 측면으로부터 기인한 것으로 보인다.

\section{노고(老苦)과 병고(病苦)}

노고(老苦)는 늙어가는 고통이다. 인간은 태어나는 순간부 터 늙어가며, 늙음은 피할 수 없다. 병고(病苦)는 병이 드는 고통이다. 노고와 마찬가지로 인간은 신체의 노화를 겪을 수 밖에 없고, 인생의 여정에서 크고 작은 병을 않게 된다. 늙음 과 병듦도 태어남과 죽음의 사이에서 연기의 법칙에 따라 벌어지는 현상임을 이해하는 것은 불교에서 중요하다.

노고와 병고는 사회심리학적 측면에서 이해해 볼 필요가 있다. Colarusso와 Nemiroff (1981)는 중년기의 성인은 젊은 
시절의 신체 혹은 신체 기능에 대한 상실을 발달 과제로 지 니면서, 의식적 및 무의식적으로, 자기애적 상처를 받으며 아동기, 청소년기, 청년기의 몸과 자신의 몸을 비교한다고 했 다. 이 과정은 인간에게 고통스러우며 노화 과정을 거부하려 는 소망과 젊은 몸의 상실을 수용하는 갈등을 보편적으로 경험하게 된다. 이러한 갈등은 중년기의 해결해야할 과제로 서 기능한다.

불교는 인생의 과정에서 벌어지는 노고와 병고를 통해 인 생의 고통을 한층 강조하면서 깨달음을 촉구한다. 동시에 늙 음과 병듦도 연기의 법칙에 따라 누구도 피할 수 없으며 이 를 받아들이는 태도를 가지도록 한다. 정신분석적 관점에서 는 늙음과 병듦을 인생의 단계에서 거쳐야할 발달과제의 측 면에서 바라보며, 비록 늙고 병드는 것을 두려워하고 회피하 려고 하지만, 삶의 유한함을 인정하고 병들고 의존하게 되는 상황이 발생할 수 있음을 받아들이는 것을 성숙의 중요한 요소로 본다. 이와 같이 나이가 들어가는 것과 병드는 것을 성인기 발달 과제의 중요한 요소로 파악한다. 이는 불교와 유사한 측면이 있으나 불교는 노고와 병고를 통해 연기의 이해를 돕고 깨달음을 강조한다면, 정신분석에서는 회피와 두려움으로 인한 고통이라는 증상에 주목하면서 삶의 유한함 의 측면에서 끝이 가까이 있다는 사실을 받아들이는(acceptance) 과정을 치료적 측면에서 관찰한다. 이는 불교가 삶을 순회형 모델로 바라보지만 정신분석은 삶을 선형적 모델로 바라보는 것으로 인해 발생하는 차이로 볼 수 있다.

\section{원증회고(怨憎會苦)}

원증회고(怨憎會苦)는 불편한 사람을 만나는 고통을 말한 다. 불교는 이러한 원증회고가 고통이라고 명시하지만 이러 한 고통도 결국 연기의 법칙에 따라 설명할 수 있다. 불편한 사람을 만나는 것 또한 조건에 따라 형성된 것이다. 자신 앞 에 불편한 사람이 무작위하게 나타난 것이 아니라, 내가 불편 한 사람을 만나게 되는 수많은 조건들이 모이고 모여 이루어 지게 된 것이다. 하지만 이러한 불편한 만남도 결국에는 조 건에 따라 소멸한다. 현재의 불편한 관계가 영원할 것 같다 는 생각은 연기를 이해하지 못하는 것이다. 원증회고는 인생 의 고통의 하나이지만 불교는 이러한 고통을 대하는 태도를 변화시킨다.

정신분석은 원증회고에 대해 불교와 다른 접근법을 취한 다. 인간관계의 불편함은 자신을 괴롭히는 사람을 만나거나, 자신과 가치관이 다른 사람을 만나는 것 등 현실에서의 불 편함을 의미한다. 인간은 자신만의 가치관과 경험이 있기 때 문에 자신과 꼭 알맞고 비슷한 사람만을 만나는 것은 불가 능하다. 하지만 심한 죄책감을 느끼거나, 상하 관계와 같은
특수한 관계가 어렵게 느껴지는 지극히 개인적인 괴로움도 있다. 정신분석은 이러한 설명이 어려운 대인관계의 문제를 유아기의 신경증적 갈등(neurotic conflict)을 통해 설명한다. Freud (1909)는 아버지 콤플렉스(father complex)가 부정적 으로 재현되는 측면을 이야기하였고, Fairbairn (1941)은 어린 시기의 양육 과정에서 내면화된 나쁜 대상관계(bad objectrelation)가 현실 세계에서 재현되면서 타인들과 과거의 고 통스러운 관계 유형을 반복하는 현상을 설명하였다. 원증회 고는 보편적인 대인관계의 불편함만을 설명하지만 정신분 석에서는 무의식에 내재되어 있는 신경증적 갈등을 중요하 게 본다는 차이가 있다. 즉, 대인관계의 불편함이 반복되거나 이해하기 어려울 때, 그 불가피성을 인정하는데 그치지 않고, 무의식적 측면에서 상대에게 자신의 대상표상을 투사해서 인식하고 반응하고 있다는 것을 이해하고 깨닫게 하는 것이 정신분석의 특징이다.

인간은 삶을 살아가는 데 있어서 대인관계의 불편함을 극 복하고 친밀함을 유지하는 것 또한 중요하다. 특히 심리사회 적 발달의 측면에서 초기 성인기에는 친밀감이 주요한 발달 과제가 된다. 다른 사람의 요구와 근심을 자기 자신의 것처럼 중요하게 생각하는 친밀감을 성취하는 것은 대인관계에서 중요한 요소가 된다(Erikson 1963). 불편한 사람을 만나는 것은 분명히 고통스러운 측면이 있지만 타인에 대한 공감과 유대감을 만드는 것은 발달 과제의 측면에서도 중요하다고 볼 수 있다.

\section{애별리고(愛別離苦)}

애별리고(愛別離苦)는 좋아하는 사람과 헤어지는 고통이다. 사랑하는 가족, 지인들과의 이별은 피할 수 없다는 것을 누 구나 경험한다. 원증회고가 조건에 따라 형성된 불편한 만남 이라면 애별리고는 조건에 따라 형성된 만남이 조건에 따라 소멸되는 것을 의미한다. 불교적 관점에서 좋아하는 사람과 의 헤어짐은 피할 수 없는 것이며, 결국 이 또한 연기의 법칙 을 따른다.

Freud (1917)는 애도(mourning)를 사랑하는 사람의 죽음 이나 상실에 대한 반응이라고 하였다. 대상과의 죽음을 포함 한 육체적 혹은 정신적 이별은 상실로써 경험되는데 애도과 정을 통해 대상에 대한 리비도를 철회하고 대상의 내재화 (introjection)와 동일시 과정을 통해 상실을 극복해낼 수 있다. 이러한 개별적 상실에 대한 반응 외에도 사회심리학적 측면 에서 중년기에는 친밀한 관계에 있는 사람들과의 이별과 죽 음을 받아들이는 것 또한 중요한 발달과제 중 하나이다.

불교적 관점에서는 애별리고는 피할 수 없는 것이지만, 결 국에는 조건에 따라 만나고 헤어짐에 대한 연기의 법칙을 
이해하고 모든 상황이 만족되는 상태로 고정되어 있지 않고 끊임없이 변화한다는 제행무상의 원리를 통찰하는 것은 중 요하다. 반면에 정신분석에서는 헤어짐이라는 상실을 정신 내적으로 극복해나가고 또한 이별의 불가피성을 받아들이 는 심리사회적 발달과제로 본다는 점에서 차이가 있다.

\section{구부득고(求不得苦)}

구부득고(求不得苦)는 구하는 바를 얻지 못할 때 발생하 는 고통이다. 인간은 항상 무언가를 원하기 때문에 고통스럽 다. 연기의 관점에서 원하는 것 또한 조건에 따라 이루어지 기도 하며 이루어지지 않기도 한다. 구하는 바를 얻었을 때는 기쁘지만 구하지 못했을 때는 인간은 고통을 겪는다. 불교적 관점에서는 구하는 바가 계속해서 이루어질 수 없음을 이해 하고 연기와 무상에 대한 통찰을 이루는 것이 중요하다.

정신분석의 관점에서 무언가를 구하는 것은 초자아의 한 요소인 자아이상과 유사하다. Bibring (1953)에 의하면 자아 (ego)가 이루고 싶은 이상적 수준(ego ideal)과 현실의 격차 (gap)가 너무 커서 그 사이를 도저히 메울 수 없을 때 우울증 이 나타난다고 했다. 정신분석은 초자아와 자아의 구조적 변 화를 통해 고통을 완화시켜 건강한 자아 이상을 이룰 수 있 도록 도울 수 있다.

또한 자아이상은 심리사회적인 발달과제로서도 의미가 있다. Colarusso (1992)는 청년기의 발달과제 중 하나로 아 동기와 청소년기에 내재화된 자아이상을 현실에 맞게 변형 시키는 것이 중요하다고 하였고, Ritvo (1976)는 청년기와 중 년기에 이르러 '현실적인 자아 이상'의 단계로 넘어간다고 하 였다. 이러한 측면에서 인간은 정신 발달을 통해 자아이상을 이해하고 현실에 맞게 변형해 나간다고 볼 수 있다.

불교적 관점에서는 구부득고는 피할 수 없고, 구하는 바를 얻거나 이루지 못함은 결국 조건에 따라 이루어지고, 조건에 따라 좌절될 수 있음을 이해하는 것이 목표가 될 것이다. 반 면에 정신분석적 관점에서는 과거의 생애를 통해 형성된 자 아이상을 현실에 맞게 수정해 나가면서 고통을 완화하는 방 식으로 접근하거나 사회심리학적 발달과제로서 인식한다. 그리고 욕망(desire)의 존재를 인식하면서 그 욕망을 행동의 동기로 전환하거나, 자아의 적절한 현실검증능력을 통해 실 현가능하도록 재조정하는 것을 고통을 감소시키는 방법으 로 이해한다.

\section{오취온고(五取蓝苦)}

오취온고(五取蓝苦)는 앞서 열거한 일곱 가지 고통을 요 약하는 고통으로 불교적 관점에서 가장 근본적이고 핵심적인 고통이 된다. 불교에서는 오취온고를 이해하는 것이 중요하다.
오취온고는 인간이 본질적으로는 오온(五藴)으로 형성되어 있는 것을 '나'라거나 '내 것'으로 취착하기 때문에 생기는 괴 로움을 의미한다(Bhikkhu Kakmuk 2010). 인간은 몸을 구성 하는 물질(色) 뿐만 아니라 마음의 작용인 느낌(受), 지각(想), 의지(行), 의식(識)이라는 다섯 요소(蘊) 각각을 '나'이거나 ‘나 의 것'이라고 생각한다. 이러한 오온도 연기의 법칙에 따라 조 건에 의해 생성되었다가 조건에 의해 변하고 사라지는 것일 뿐이며, 불변의 실체인 자아가 별도로 존재하는 것은 아니다. 인간은 오온으로 이루어져 있기 때문에 순간적으로 구성되고 사라지는 영원불멸의 존재가 아님에도 불구하고 '자기'라는 존재가 있다고 착각한다. 불교는 모든 고통이 결국은 '실체적 존재로서의 자기 있음'이라는 착각에서 비롯된다고 본다 (Choi와 Shin 2005). 붓다의 관점에서 보면 인간은 지속적으 로 변화하는 육체와 정신적인 요소들의 집합일 뿐이며, 끊임없 이 변화하는 물질적, 정신적 힘이나 에너지의 결합일 뿐이다.

불교는 모든 존재와 현상이 고통인 이유는 결국 세상은 무아이기 때문으로 설명한다. 자기라는 실체는 어디에도 존 재하지 않기 때문에 세상은 고통스러우며, 인간은 자기라는 실체가 있다고 착각하기 때문에 고통스럽다는 것이다. 그리 고 이러한 자기에 대한 집착은 영원불멸하는 자기에 대한 환상을 토대로 한다. 불교는 이러한 실체화된 자아 혹은 영 원불멸하는 자기가 없음을 무아를 통해 이해함으로써 통찰 을 일으키고 삶과 자기에 대한 근본적인 태도를 변화시킨다. 위와 같은 불교의 무아 사상은 동양 문화권에 지대한 영향 을 끼쳐왔다. 반면에 서양에서는 건강한 자아, 건강한 자기 의 역할을 강조한다. 서양 문화권에서 태동한 정신분석은 자 아 기능을 강하게 만들고 자기를 건강하게 만드는 것을 목 표로 하지만 불교는 자기 혹은 자아 자체가 허상이라고 하 는 측면에서 둘 간의 차이점을 보인다. 이러한 자기 혹은 자 아에 대한 접근법에 대한 차이는 최종적인 치료 목표에서도 차이를 보인다. 불교는 오온으로 형성되어 있는 인간 역시 무상의 원리에 따라 끊임없이 변화하며 일시적으로 구성되 어진 존재라는 인식을 바탕으로 한다. 결국 실체화되고 고정 된 자기가 존재하지 않는다는 무아를 통찰하는 것이 중요하다.

불교와 정신분석이 치료적인 접근법과 최종적인 목표의 차이가 있다고 하더라도, 자기에 대한 불교의 인식은 다양한 정신분석적 관점에서 해석해 볼 수 있다.

\section{고전적 정신분석}

고전적 정신분석의 관점에서 인간의 자기에 대한 집착은 리비도를 자기(self) 혹은 자아(ego)에게 부착하려는 경향성 이라고 해석할 수 있다. Freud (1914)는 아이가 생애 초기에 자신의 몸으로부터 성적 만족을 얻는 자기성애(autoero- 
tism) 단계를 시작으로 자기애(narcissism) 혹은 자아-리비 도(ego-libido)의 단계를 거쳐, 대상-리비도(object-libido) 로 발달한다고 했다. 초자아의 한 요소인 자아 이상 (ego ideal)은 어린 시절의 잃어버린 자기애이며, 인간은 자아 이 상의 욕구를 충족시킴으로써 원시적인 자기애 상태의 전지 전능함(omnipotence)을 회복한다고 하였다.

이러한 관점에서 모든 인간은 어린 시절의 잃어버린 자기 애를 다시 되찾고자 하는 욕구를 가지고 있다. 인간의 자기 에 대한 무의식적인 집착은 자기의 불멸과 영원성에 대한 잘못된 믿음이라는 측면에서 전지전능함으로의 복귀를 위 한 잃어버린 자기애를 추구하는 과정의 고통과 같다.

Freud는 자아이상(ego ideal)과 이상적 자아(ideal ego)는 구분하지 않았지만 Hanly (1984)는 이 둘을 상세히 구분하 였다. Hanly에 따르면 '이상적 자아'는 자아가 저절로 가지 는 하나의 이상으로 실제 자아에 대한 이상화된 이미지이고 '자아 이상'은 자아가 갈망하고, 그것이 되기를 열망하고, 그 속에 통합되고 융합되거나 결합할 수 있기를 욕망하는 것이 다. 이상적 자아는 이상화에 의해 왜곡된 자아 이미지이지만, 자아 이상은 성취되는 완벽함을 나타내고, 현실화되지 않은 잠재된 상태가 된다(Epstein 2007).

불교에서 이야기하는 영원하고 불멸하는 자기에 대한 인 간의 무의식적 집착은 Hanly의 이상적 자아 개념을 통해 더 욱 잘 설명될 수 있다고 저자들은 생각한다.

\section{자아 심리학}

불교에 따르면 인간이라는 존재는 다양한 조건에 따라 끊 임없이 생성되고 소멸되는 존재로 실체화된 자기가 없다. 이 러한 무아에 대한 통찰이 없을 때 인간은 자기 자신이 영원 불멸하고 고정된 자아가 존재한다고 착각한다. 끊임없이 변 화하는 자기에 대한 부정은 변화에 대한 거부를 일으키고 변화에 대한 거부는 고통을 낳는다.

이러한 불교의 고통에 대한 설명은 정신분석에서의 저항 (resistance)과 유사한 측면을 보인다. 자아 심리학에서 자아 는 본능(Id), 초자아(superego) 그리고 외부 현실간의 갈등을 타협시키는 측면을 맡는다. 특히 자아는 삶의 경험을 통해 세상에 적응해나가는 나름대로의 방식을 채택하게 되고, 평 형상태를 유지하려 하는 습성이 있다. 그러므로 성격과 증상 이란 것도 결국 나름대로 굳어진 평형상태라고 할 수 있다 (Ha와 Yu 2007). 인간의 굳어진 평형상태가 깨지는 상황은 인간에게 의식적으로 혹은 무의식적으로 강력한 위협을 안 겨준다. 인간은 누구나 자신들에 관한 통찰을 원하면서도 동 시에 두려워하고 거부하기 쉽다는 이율배반적인 특성을 지 니기 마련이며, 이러한 역설은 매우 자연스럽고 당연한 현상
이다(Lee 2006).

불교는 모든 것은 끊임없이 변화한다는 무상과 실체화된 자기가 존재하지 않는다는 무아의 원리를 바탕으로 고통을 설명한다. 불교적 관점에서 인간 고통의 기저에는 변화에 대 한 거부와 영원불멸하는 자기에 대한 착각이 있다. 정신분석 에서 이야기하는 저항은 변화를 두려워하는 인간의 측면을 보여준다는 면에서 무상을 거부함으로 일어나는 고통과 유 사점을 보이며, 변화를 거부하고 현재의 고통스러운 자신을 유지하고자 하는 습성은 무아를 이해하지 못함으로써 일어 나는 고통과 유사하다고 볼 수 있다.

\section{대상관계 이론}

대상관계 이론에서의 정신 발달은 안정된 자기-대상표상 의 획득을 중요시한다. 어린 시절에 형성된 자기표상과 대상 표상, 그리고 이 둘을 연결 짓는 대상관계 패턴은 일생을 통 해서 반복된다는 것이 대상관계 이론의 설명이다.

불교에서 설명하는 고정된 자기에 대한 인간의 집착은 무 의식적으로 내재화된 자기표상이 삶을 통해서 지속적으로 반 복되는 것으로 이해할 수 있다. 고정되고 불변하는 자기에 대 한 인간의 집착은 무의식적으로 내재화된 자기표상과 유사하 며, 이러한 자기표상은 자기에 대한 인식, 판단, 느낌과 함께 결부되어 있어, 결국은 인생을 통해 영향을 미치게 된다.

대상관계 이론에서는 어린시절 내재화된 자기표상이 대 상표상과 짝을 이루어 이러한 대상관계 패턴이 인생을 통해 반복적으로 영향을 끼친다는 선형적 관점을 취한다는 점에 서 불교와의 차이점을 보이지만 고정적인 자기를 고집하고 변화를 거부하는 인간의 습성을 이해하는 측면에서 유사점 이 있다고 볼 수 있다. 정신분석에서 인간 개인이 자기라고 믿고 있고 고집하던 자기표상을 이해하게 되고 자기에 대한 인식을 확장하는 것을 목표로 한다는 점은 불교와 최종목표 는 다를지라도 그 방향성이 유사하다고 저자들은 생각한다.

\section{자기심리학}

자기심리학은 자기애적 추구를 인간이 선천적으로 갖고 태 어난다고 주장한다. 자기가 정동을 조절하고 자기대상(selfobject)과의 상호작용을 활용할 수 있는 능력이 있다면 건강 하다고 여긴다(Kohut 1971)

서양 문화권에서는 인간이 지닌 자기 감각(sense of self)이 매우 중요하다. 자기 감각은 일을 할 수 있는 능력과 논리적 인 사고, 정동과 충동을 조절하는 자기의 능력으로 나타난다. 자기심리학 관점에서 생애 초기에 자기애가 적절히 충족되 지 못하면 자기애는 취약해진다. Freud (1914)는 어떤 인간 도 아동기에 지배적이던 자기애적 완벽함에 대한 소망을 포 
기할 수 없다고 했다. 또한 유아기의 사랑의 상실과 실패는 자기애적 상처의 형태로 자존심에 영원한 상처를 남긴다고 하였다(Freud 1920). 이러한 상처는 결국 남은 인생에서 불 완전하고 불확실한 자기에 대한 불안을 낳게 된다. 정신분석 은 취약한 자기애를 건강한 자기애로의 변화를 추구한다. 반 면에 불교에서는 자기애 자체를 환상으로 바라보며 자기애 를 완전히 벗어나는 것을 목표로 한다. 불교는 자기애가 건 강한지 건강하지 않은지의 문제가 아니라 자기애 자체의 문 제로 나아간다. 불교는 자기라는 개념에 대한 근본적인 부정 을 시도하며, 자기애는 이러한 자기 개념을 일으키는데 핵심 이 된다.

불교적 관점에서 보면 자기에 대한 모든 개념은 잠정적으 로 만들어진 것이고 망상에 가깝다. 인간은 안정성을 주는 것은 무엇이든지 그것에 헛되이 집착하려는 경향성을 내재 한다. 인간이 자기에 대한 개념화와 자기 개념과의 동일시를 이루려는 경향은 결국 불안정한 자기를 안정화시키려는 시 도에서 비롯된다. 불교는 자기 개념화 자체를 거부하고 뛰어 넘는다. 자기와 관련된 어떤 개념이 아무리 솔깃하다고 해 도, 자기와 그 개념을 동일시하는 것은 실제로 불필요하며 오히려 불만족을 준다는 것이다(Epstein 2007).

실제 자기와 자신이 바라는 자아개념 사이에는 분명한 불 일치가 있다. 진정한 자기-분석(self-analysis)이 불가능하다 는 Freud의 언급도 비슷한 맥락으로 보인다(Freud 1897). 불 교는 수행을 통해 이러한 불일치를 통찰하고 자기 자신에 대한 객관적인 인식을 확장시키는 것을 추구하지만 최종 목 표는 자기의 소멸, 무아이다. 불교와 정신분석은 자기-인식, 자기-통찰을 넓힌다는 면에서 지향하는 바는 같으나, 최종 목표는 다르다고 볼 수 있다.

\section{결 론}

고는 불교에서 중요한 위치를 차지하고 있으며, 다른 어떤 주제보다 불교의 핵심적인 주제이다. 저자들은 불교의 고에 대해서 불교의 핵심 교리인 삼법인을 먼저 설명하고 사성제 중 첫 번째 진리인 고성제의 각각의 고통들을 정신분석적인 관점에서 해석해보았다.

불교는 모든 삼라만상은 고통(일체개고)이라고 하면서 연 기의 법칙에 따라 그 원인을 모든 것은 변화한다는 것(제행 무상)과 고정된 실체는 존재하지 않는다는 것(제법무아)으 로 설명한다. 불교의 고통에 대한 인식은 우주론적인 보편성 으로부터 출발하며 무상과 무아를 통찰하는 것을 통해 고통 을 해결하고자 하는 반면, 정신분석은 정신발달 및 생애 초 기의 경험들을 통해 고통을 설명하고 환자로 하여금 개개인
의 과거를 분석하여 통찰함으로써 해결하고자 한다는 측면 에서 차이를 보였다.

또한 고성제에서 오취온고를 제외한 일곱 가지 고통에 대 해서 불교는 죽음에 대한 문제를 전면에 배치시키고 연기의 법칙에 따라 끊임없이 변화하는 무상의 원리를 강조하는 반 면, 정신분석은 심리사회적 발달 과제의 측면에서 해석해 볼 수 있었다.

오취온고는 불교에서 핵심이 되는 고통이다. 불교는 고정 되고 실체화된 자기에 대한 인간의 집착하는 경향을 직면시 키고 무아를 이해함으로써 고통을 해결하려고 하는데, 이러 한 인간의 자기에 대한 집착에 대해서 다양한 정신분석적 관 점에서 해석해보았다. 서양문화권에서 태동한 정신분석은 건강한 자기 감각을 중요시하지만 불교는 이러한 자기 감각 자체를 허상으로 파악한다는 데 있어 차이점을 보였다.

고정된 자기를 완전히 부정하고, 자기에 대한 개념화와 동 일시를 거부하는 무아의 개념은 정신분석과 불교에서 최종 목표의 차이점을 드러낸다고 볼 수 있다. 정신분석이 개인의 과거 경험으로부터 현재를 이해하는 과정을 중요하게 여기 는데 반해, 불교는 세상의 무상과 무아를 통찰하면서 존재론 적인 현실을 직시하는 차이가 있다.

저자들은 총 2 부로 구성된 본 논문에서 고성제를 다룬 1 부 의 논문을 마무리하고, 고통의 원인인 집성제와 정신 치료적 고려에 대해서는 2 부의 논문에서 다루어보고자 한다.

\section{Acknowledgments}

None

\section{Conflicts of Interest}

The authors have no potential conflicts of interest to disclose.

\section{Author Contributions}

Conceptualization: Jee Hyun Ha, Hyeong Hoon Kim. Data curation: Hyeong Hoon Kim. Formal analysis: Jee Hyun Ha. Investigation: Jee Hyun Ha, Hyeong Hoon Kim. Methodology: Jee Hyun Ha. Project administration: Jee Hyun Ha. Resources: Jee Hyun Ha, Hyeong Hoon Kim. Supervision: Jee Hyun Ha. Validation: Jee Hyun Ha. Visualization: Jee Hyun Ha. Writing — original draft: Hyeong Hoon Kim. Writing — review \& editing: Jee Hyun Ha.

\section{ORCID iDs}

Hyeong Hoon Kim https://orcid.org/0000-0002-4071-0539

Jee Hyun Ha https://orcid.org/0000-0002-0973-1139

\section{REFERENCES}

An OS. Life and death from Buddhist perspective: pursuing life freeing from samsara. J Soc Philos Stud 2006;(75):21-51.

Auchincloss EL. The psychoanalytic model of the mind. Arlington, VA: American Psychiatric Publishing;2015.

Bhikkhu Kakmuk. Understanding of early buddhism. Ulsan: Nibbana Buddhist Education Foundation;2010. 
Bibring E. The mechanism of depression. In: Greenacre P. Affective disorder: psychoanalytic contributions to their study. New York: International Universities Press; 1953. p.13-48.

Choi HD, Shin SW. Psychotherapeutic significance of the Buddhist thought of 'not-self' (Anatta). J Korean Neuropsychiatr Assoc 2005; 44:754-762.

Colarusso CA. Child and adult development: a psychoanalytic introduction for clinicians. New York: Plenum Press;1992.

Colarusso CA, Nemiroff RA. Adult development: a new dimension in psychodynamic theory and practice. New York: Plenum Press;1981.

Epstein M. Psychotherapy without the self: a Buddhist perspective. New Haven: Yale University Press;2007.

Erikson EH. Childhood and society. 2nd ed. New York: W. W. Norton;1963. p.31.

Erikson EH. The human life cycle. In: Sills DL. International encyclopedia of the social sciences. New York: Macmillan;1968. p.286-292.

Fairbairn WRD. An object-relations theory of personality. New York: Basic Books; 1941.

Freud S. Notes upon a case of obsessional neurosis. In: Strachey J, editor and translator. The standard edition of the complete psychological works of Sigmund Freud. Vol.10 (1909). London: The Hogarth Press; 1955. p.145-156. (Original work published 1909)

Freud S. Beyond the pleasure principle. In: Strachey J, editor and translator. The standard edition of the complete psychological works of Sigmund Freud. Vol.18 (1920-1922), beyond the pleasure principle group psychology and other works. London: The Horgarth Press; 1955. p.1-64. (Original work published 1920)

Freud S. On narcissism: an introduction. In: Strachey J, editor and translator. The standard edition of the complete psychological works of Sigmund Freud. Vol.14 (1914-1916): on the history of the psycho-analytic movement, papers on metapsychology and other works. London: The Horgarth Press;1959. p.67-102. (Original work published 1914)

Freud S. Instincts and their vicissitudes. In: Strachey J, editor and translator. The standard edition of the complete psychological works of Sigmund Freud. Vol.14 (1914-1916): on the history of the psycho-analytic movement, papers on metapsychology and other works. London: The Horgarth Press;1959. p.109-140. (Original work published 1915)

Freud S. Thoughts for the times on war and death. In: Strachey J, editor and translator. The standard edition of the complete psychological works of Sigmund Freud. Vol.14 (1914-1916): on the history of the psycho-analytic movement, papers on metapsychology and other works. London: The Horgarth Press;1959. p.273-301. (Original work published 1915)

Freud S. Mourning and melancholia. In: Strachey J, editor and translator. The standard edition of the complete psychological works of Sigmund Freud. Vol.14 (1914-1916): on the history of the psycho-analytic movement, papers on metapsychology and other works. London: The Horgarth Press;1959. p.243-248. (Original work published 1917)

Freud S. Civilization and its discontents. In: Strachey J, editor and translator. The standard edition of the complete psychological works of Sigmund Freud. Vol.21 (1927-1931), the future of an illusion, civilization and its discontents, and other works. London: The Press; 1961. p.57-146. (Original work published 1930)

Freud S. Letter from Freud to Fliess, November 14 1897. In: Masson JM. The complete letters of Sigmund Freud to Wilhelm Fliess, 18871904. Cambridge: Havard University Press;1985. p.278-282.

Freud S, Breuer J. Studies and hysteria. In: Strachey J, editor and translator. The standard edition of the complete psychological works of Sigmund Freud. Vol.2 (1893-1895): studies on hysteria. London. Horgarth Press;1957. p.255-305. (Original work published 1895)

Hanly C. Ego ideal and ideal ego. Int J Psychoanal 1984;65:253-261.

Ha JH, Yu J. Manifestations of resistance. Psychoanal 2007;18:112-117.

Kim SK. A brief note on psychoanalysis and Buddhism. Psychoanal 2001;12:30-34

Kohut H. The analysis of the self: a systemic approach to the psychoanalytic treatment of narcissistic personality disorder. New York: International Universities Press; 1971.

Kostner D. It's not just about the mindfulness: foundations of buddhist thought and why it matters for psychoanalysis. In: Hoffer A. Freud and the Buddha: the couch and the cushion. London: Karnac Books;2015. p.25-50.

Lee BW. Transference and resistance. Psychoanal 2006;17:33-40.

Olendzki A. Wisdom in buddhist psychology. In: Germer CK, Siegel RD. Wisdom and compassion in psychotherapy. New York: Guilford Press;2012. p.121-137.

Ritvo S. Adolescent to woman. J Am Psychoanal Assoc 1976;24(5 Suppl):127-137. 